\title{
Information Technology In Improving Quality And Effectiveness of Education In Indonesia
}

\author{
${ }^{1}$ Dian Fithra Permana, ${ }^{2}$ Husaini Usman \\ ${ }^{1}$ dianfithrapermana.df@gmail.com, ${ }^{2}$ husainiusman@gmail.com \\ 1,2 Management of Education Yogyakarta State University Yogyakarta, Indonesia
}

\begin{abstract}
This article was made to find out the steps of using information technology in the world of education in Indonesia. The method used is a qualitative method with a library research approach by analyzing the empirical findings that have been carried out and adding the researchers' thoughts as their contribution. The findings in this study are steps in the development of information technology in the world of education in Indonesia include designing database applications; designing web-based learning applications, portals, interactive media, which contains tutorial and learning tool applications; TV optimization education. While the use of information technology to improve the quality and effectiveness of the educational process is by managing information systems (SIM), elearning, interactive learning media and skill education.
\end{abstract}

Keywords: Information technology, education, Indonesia.

\section{Introduction}

Education is a process for increasing human position which is viewed from the three most basic things, namely affective which is a reflection of the level of piety, faith, character, character, competence, and good personality; cognitive that can be measured from the thinking capacity and intellectual ability to explore and develop science and technology; and psychomotor which is a measure of optimal development of technical skills, skills and kinesthetic competencies. For education is a strategic place for efforts to develop individual potential so that the achievement of full human development in Indonesia can be achieved.

The realization of complete Indonesian human development requires equal education services for Indonesian citizens. Therefore, efforts to improve public access to quality education is something that must be implemented by Indonesia in accordance with the objectives of the country listed in the 1945 Constitution which reads protecting all nations and all of Indonesia's bloodshed, educating the life of the nation, advancing the general welfare and participating in world order based on independence, eternal peace, and social justice. The importance of education for all Indonesians is reflected in article 28 B verse 1 that every citizen has the right to develop themselves and fulfill the basic needs, have the right to get education and benefit from science, technology, art, culture, and improving the quality of life for human welfare. Furthermore, Article 31 paragraph 1 which contains every citizen has the right to education.

Of the objectives at the opening of the 1945 Constitution and several articles in the body of the 1045 Constitution, educational institutions play an important role in helping the government strive for quality, effective and capable education to produce quality, creative, competitive and productive Indonesian human output. But now Indonesia is still faced with the low quality of education that has taken place. This can be seen from in 2011 the EFA 
(Education for All) data released by UNESCO revealed that EDI (Education Development Index) of 0.934 in value made Indonesia ranked 69th out of 127 countries in the world.

In overcoming this, one of the things that can be done is to utilize information technology in carrying out education. This is based on the reality that exists in several countries. There the use of information technology in the implementation of education has been proven to improve the quality of education. The following is an example of the success of several countries in utilizing information technology in education.

a. At various universities in Spain, ability campus information systems to integrate students into broad and diverse a network of relationships and personal contacts while at university and beyond are valuable benefits to be offered to student. [1].

b. At Isfahan University of Medical Science IT selection and implementation can improve quality improvement process through facilitate data collection and steps analysis[2].

The above facts show that information on computer technology connected to wireless networks or the internet can contribute significantly to education. Interactive technology contributes to fundamental changes to manual systems to technology-based systems. Students can access up-to-date information and get ease in carrying out all activities in education. Thus, information technology is one way to get better and better quality education.

\subsection{The Structure}

a. The problem that arises in this study is that the low quality of education in Indonesia is reflected in the results of a survey from UNESCO and EFA (Education for All) data. A good management is needed in formulating a strategy so that Indonesia can achieve quality education goals from its input, process and output.

b. This research is considered important because it can contribute to the world actors of Indonesian education in the management of information systems in the world of education in Indonesia.

c. Through the use of information technology, we can achieve a quality educational goal from input to output where previously it was not known what and how the use of information technology was made and implemented.

d. Through analysis conducted from the results of research and also the existing literature on management information systems in the world of education, researchers can provide ideas or arguments about how information management systems can improve the quality of education, especially in Indonesia.

e. Because of the wide scope of management and the limitations of researchers over time, cost, and energy, this research is only focused on management information systems in improving the quality and effectiveness in Indonesia.

\section{Literature Review}

\subsection{Information Technology}

Information technology is a technology that combines computers with high-speed communication networks, which contain data, video and sound[3]. In information technology itself there are 2 basic components, namely computer technology and communication technology. Computer technology is a computer-related technology and its application includes computer-related equipment. While communication technology is a technology related to remote communication devices, eg television, telephone, fax. 
Information technology is interpreted as the knowledge needed to carry out management in information so that information can be traced back easily and accurately, information is data that has been processed and can be stored in the form of sound, writing, live images, and dead images. While the data processed through information technology can be in the form of knowledge and knowledge itself[4]. Information can be of small and large capacity, if the information is of small capacity, no process is required with certain techniques and procedures in storage. If large-capacity information is needed, techniques and procedures for storage are needed. This storage technique and procedure is called information technology.

From the above understanding, it can be argued that information technology is seen as the knowledge needed to carry out the management process or manage information so that it can be found quickly and easily. In its implementation in order to be able to manage well, effectively and efficiently, computer technology is needed as an information processor and communication technology as a means of delivering information remotely.

\subsection{Information Technology in Improving Educational Quality and Effectiveness}

Information technology is developing rapidly and has the potential to improve the quality of education. The internet as a direct derivative of information technology contains unlimited things that can be used for the benefit of educational development. The internet makes learning no longer borders on time and space.

In the world of education, information technology provides a means that can be used to carry out learning in the same direction and interactively. The state of Indonesia which is separated from the island and the sea which is scattered from Sabang to Merauke makes the use of information technology felt very important. Information technology enables the implementation of distance education. This has an impact on equity in education in Indonesia, from unreached areas of transportation to affordable transportation. From this it can be revealed that information technology in education has a crucial meaning, especially in terms of education equality and increasing the effectiveness and quality of education provision in Indonesia.

The use of information technology in education can be carried out with several steps of development, among others

a. Designing database applications in which there is data storage and processing of academic information including lecture systems, assessments, curriculum information, education management, and learning materials.

b. Designing web-based, portal, interactive media learning applications, which include tutorials and learning tools.

c. Improve the quality of education by utilizing TV education as a material of enrichment.

d. Gradual implementation of the system from narrow things to broad matters. This facilitates the management of the use of information technology in the process of implementing education.

The implementation of the use of information technology in the implementation of education, especially in Indonesia can be carried out in the following ways.

a. Information System Management

Information management (SIM) is an information system that supports management processes in an organization. Time efficiency, organizational transaction material, support for operations, management and decision-making functions can be supported by a good 
SIM. Information technology in running information systems results in fast and accurate information rates. Education offices and schools that have created online databases make it easy to exchange information and data quickly. The ease that occurs is the efficiency of the implementation of education in everything.

An online data base in the form of academic information systems in educational institutions makes it easy for parents to get information about their child's learning progress whenever needed. Other facilities that can be produced include convenience for the community, students, or anyone interested in getting the information needed. Interactive WEB created by educational institutions facilitates the flow of institutional communication with the community. Information from educational institutions such as vision, mission, awards, achievements, and others can be easily accessed by the community which has an impact on increasing public interest in the institution. Academic WEB makes it easy for teachers, students, employees, parents, and the community to obtain information for example academic progress, daily development, administration, registration, and so on.

b. E-learning

E-learning is information technology in the field of education. Through e-learning the learning process is no longer limited in time and space[5]. Learning anytime, anywhere, creativity-based independent learning, students can analyze knowledge, explore, process, and utilize information is something that can be done in e-learning.

The internet is used in e-learning based learning, so the source of knowledge does not only come from teachers, but also anyone from any part of the world. Facility products from e-learning include e-books, e-libraries, expert communication experts, mailing lists, news groups, e-mails, web, and so on. Sites in e-learning in Indonesia include education.net, educasi.net, physic.net, computer science, plasa.com, pintarmedia.com and so on.

Universities and schools are expected to be able and able to implement the implementation of each e-learning. In simple terms lecturers or teachers can create their own site by linking the learning material in it as well as the tasks and evaluations for students.

c. Interactive Learning Media

The use of interactive learning media obtained from the use of information technology through the internet and e-learning is expected to improve students' thoughts, interests, attention, feelings in the learning process. The use of interactive learning media can reduce the delay in communication so that learning is more effective.

Some students find it easier to manage information learning visually, sound (audio), and practice, information from what is read can be absorbed as much as $10 \%, 20 \%$ of what is heard, $30 \%$ of what is seen, $50 \%$ of vision and hearing, $70 \%$ of words, and $90 \%$ of what was done[6]. The results of the study emphasize that computers qualify as effective learning media, because they are able to provide information in the form of text, graphics, audio, video, and animation, and their use involves skills.

The use of information technology as a learning medium can be categorized into 3 groups, namely

(1) CAI (Computer Assisted Instructional) Information Technology or CBT (Computer Based Training). In this case learning material is packaged in software. Learners can learn how to run a program in computer. The use of information technology in this 
way can provide direct feedback to students in the form of learning progress through the recording of learning evaluation results.

(2) Utilization of information technology as a medium for delivering material through the internet. Learning materials are made in the form of webpages, or interactive learning programs (CAI or CBI). Material is placed on the server so that it can be downloaded via a web browser or file transfer protocol (file sender application)

(3) Information technology is used in communicating with experts, resource persons, and other students. Communication can be in the form of consultation on things that are not understood, expressing opinions that can be responded by friends or teachers. This makes students get feedback from experts, friends, resource persons, or teachers regarding subject matter.

d. Skill Education

Computers are needed in various fields of work. Computer use skills are skills that are needed in today's life in order to compete in various fields.

Information technology education contains skills that can be developed both specific life skills and general life skills. Skills in operating computers using existing programs in the form of applications and programming are basic skills. While surfing skills with the internet to explore, process, and utilize information are general life skills.

\section{Material \& Methodology}

\subsection{Data}

Data in this study obtained from the results of research that has been done, which has been tested empirically the truth here the researcher only analyzes and compares then gives thoughts and contributions by adding the results of the researchers' thoughts.

\subsection{Method}

This research method is qualitative research with library research approach. The researcher analyzed the data obtained from the research results and existing literature and added the researchers' thoughts as their contribution.

\section{Results and Discussion \\ 4.1 Result}

The results of this article's exposure include steps that must be taken in the development of information technology in the world of education, especially in Indonesia, namely designing database applications; designing web-based learning applications, portals, interactive media, which contains tutorial and learning tool applications; TV optimization education as material enrichment. While the use of information technology to improve the quality and effectiveness, and the efficiency of the educational process is with information system management (SIM), e-learning, interactive learning media and skill education.

\subsection{Discussion}

Information technology is a common thing that must be mastered by every individual to survive in the globalization competition. In the world of education the Management Information System (SIM) has become an absolute thing to do. The perpetrators of education in Indonesia have gradually taken steps to utilize information technology in carrying out education. They try and continue to try to implement a management information system (SIM) 
in order to use information technology in educational institutions. Even so, the mlanhgkah that is deemed not optimal because the implementation of learning in Indonesia in general has not implemented an e-learning system as for the reason that there is still limited internet network to the regions especially outside Java. It is better for the government and actors in the world of education to always try to implement a management information system in learning even though it is slowly and gradually.

\section{Conclusion}

a. From this article we can find out the steps in the development of information technology and its use in the world of education, especially in Indonesia.

b. Information technology becomes very important in this era of globalization, including in the world of education in the future it will be better if information technology is truly utilized in the world of education, especially in Indonesia as a whole.

c. The use of information technology in this article has been raised with its steps, especially for Indonesia, how steps must be taken so that the use of information technology in the world of education has been raised by the author.

d. With the steps to use information technology for the world of education, it is expected to be a reference for the government and actors in the world of education to utilize information technology more optimally for the world of education.

e. For future research, it is expected to be able to discuss in more detail about the use of information technology in the world of education, not only in Indonesia, maybe in some countries or the world and more deeply up to its implementation.

\section{Acknowledgement}

This article is fully supported by the Yogyakarta State University where the author studied and got a menullis experience. Thank you to Prof. Dr. Husaini Usman, M.Pd., MT who always guides the writing of this article. Thanks to Mr. Didied Riyatno for encouraging financially so that this article can be resolved.

\section{References}

[1] C. J., Bernardo, M, Cobarsí, \& G, "Campus-Wide Information Systems," Campus Inf. Syst. students Classif. Spain, vol. 25, no. 1, pp. 50-64, 2008.

[2] R. Changiz, T., Moeeny, A., \& Jowshan, "Campus-Wide Information Systems," OFIS, vol. 2, no. 2, pp. 95-100, 2004.

[3] C. Abdul, Kadir \& Terra, Pengenalan Teknologi Informasi. Yogyakarta: Andi Offset, 2004.

[4] N. W. Syam, "eknologi Informasi dan Komunikasi dalam Dunia Pendidikan," 2004.

[5] O. W. Purbo, "Teknologi e-learning," Jakarta: Elex Media Komputindo, 2002.

[6] D. Bobby, Quantum Learning. Jakarta: Kaifa, 1999. 